\title{
Carbon-coated stainless steel as a bipolar plate material in PEM water electrolyzers
}

\author{
Sebastian Proch ${ }^{1, *}$, Ulf Bexell ${ }^{1}$, Claire Moffatt ${ }^{1}$, Mikael Stenström ${ }^{1}$, Carlos Bernuy-Lopez ${ }^{1}$, Jörgen Westlinder ${ }^{1}$, Hans \\ Becker $^{2}$, Graham Smith ${ }^{2}$, Edmund J.F. Dickinson ${ }^{2}$, Gareth Hinds $^{2}$, Vincent Wilke ${ }^{3}$, Svenja Stiber $^{3}$, and Aldo Gago ${ }^{3}$ \\ ${ }^{1}$ Surface Research, Strategic Research, AB Sandvik Materials Technology, 81181 Sandviken, Sweden \\ ${ }^{2}$ National Physical Laboratory, Hampton Rd, TW11 0LW, Teddington, United Kingdom \\ ${ }^{3}$ German Aerospace Center (DLR), Institute of Engineering Thermodynamics, Pfaffenwaldring 38-40, 70569 Stuttgart, Germany
}

\begin{abstract}
The kinetically sluggish oxygen evolution reaction in proton exchange membrane water electrolyzers (PEMWEs) leads to high potentials of $>1.5 \mathrm{~V}$ vs RHE at the anode electrode during operation. In contrast, an investigation with an in situ reference electrode indicates a much lower potential at the anode side of the bipolar plate which would allow the use of stainless steel and carbon as the bipolar plate materials. This decoupling is induced by the low conductivity of the circulating deionized water. In single cell electrolyzer tests, we show that carbon-coated $316 \mathrm{~L}(\mathrm{C}-316 \mathrm{~L})$ stainless steel is suitable as a bipolar plate material in contact with the anode and cathode sides of the PEMWE. The coating remains stable throughout the experiments, i.e., $720 \mathrm{~h}$ at the anode and $1000 \mathrm{~h}$ at the cathode side. Based on these results we regard carbon-coated stainless steel as a sustainable solution for the large-scale application of PEM water electrolysis since it might replace (Pt-coated) titanium in the bipolar plate.
\end{abstract}

\section{Introduction}

Hydrogen production via electrolysis of water has the potential to make a significant contribution to decarbonization of energy. The two mature electrolysis technologies are alkaline electrolysis using concentrated aqueous $\mathrm{KOH}$ as electrolyte and PEM electrolysis, which replaces the aqueous electrolyte with a proton conducting membrane [1]. The low ohmic resistance of thin polymer membranes, e.g., Nafion, in comparison to aqueous solutions facilitates higher current densities and, therefore, a smaller physical footprint of PEMWEs. Moreover, it has been proposed that membrane electrolysis allows faster response towards electricity from renewable sources [2]. Hence, PEM electrolysis is considered a promising option for green hydrogen production.

However, competitive costs for $\mathrm{H}_{2}$ need to be achieved, which can be accomplished by lowering the electrolyzer's operational and capital expenditures (OPEX and CAPEX). OPEX is mainly associated with input electricity driving the endoergic water splitting reaction. Renewable electricity costs will drop in the future due to falling prices of solar PV panels [3] and other renewable electricity sources like wind turbines [4] due to their continued deployment. Consequently, it seems more beneficial to focus on decreasing the CAPEX.

A major cost driver of PEMWEs is the need for highly corrosion-resistant (Pt-coated) titanium components used within the anode compartment; they are often used on the cathode side too. Their use is based on the widely accepted perception that the high potential at the anode electrode ( $>1.5 \mathrm{~V}$ vs RHE [5]) leads to an exceptionally corrosive environment across all the anode components [6]. This view of the anode has been challenged recently by experiments in which an in situ reference electrode demonstrates decoupling of the current collector from the catalyst layer. The observed 'galvanic' decoupling is attributed to the very low ionic strength of the electrolyzer feed water [7].

This effect results in a potential at the bipolar plate that is less oxidative than expected, creating the opportunity to use less corrosion-resistant and, therefore, more cost-effective materials, like stainless steel and carbon, in the anode compartment. In other words, the complete bipolar plate and parts of the porous transport layer could be substituted by stainless steel and carbon components with significant opportunity for cost reduction. We demonstrate the validity of one part of this suggestion by investigating the use of $316 \mathrm{~L}$ and carboncoated 316L (C-316L) stainless steel flow plates at the anode and cathode side in single cell PEM water electrolysis experiments.

\section{Experimental}

C-316L was manufactured by removing the oxide layer of a bright-annealed $316 \mathrm{~L}$ strip (plasma etching) and subsequently coating it with a metallic adhesion layer and

\footnotetext{
* Corresponding author: sebastian.proch@sandvik.com
} 
carbon in a coil-to-coil, high-throughput physical vapor deposition (PVD) coating line. The production process aims to achieve a $35 \mathrm{~nm}$ carbon layer and a $95 \mathrm{~nm}$ adhesion layer, but variations of these values are to be expected over large areas.

Single cell experiments at the anode side with and without an in situ reference electrode were presented previously [5]. The in situ reference electrode comprises a reversible hydrogen electrode (RHE, Hydroflex, Gaskatel, Germany) immersed in a chamber filled with $0.5 \mathrm{M} \mathrm{H}_{2} \mathrm{SO}_{4}$ connected to the cell using a Nafion tube sealed with an O-ring and a polyetheretherketone (PEEK) monofilament to prevent acid leakage. The measured current collector potential $\left(\mathrm{E}_{\mathrm{BPP}}\right)$ is the potential between the anode current collector (working electrode) and the reference electrode. The end tip of the salt bridge is positioned at the surface of the metal sheet sample facing the expanded Ti metal mesh. A schematic representation of the anode side components is shown in Fig. 1.

Auger electron spectroscopy (AES) sputter depth profiling, catalyst coated membrane (CCM) digestion and subsequent trace metal analysis by inductively coupled plasma sector-field mass spectrometry (ICP-SFMS) [8] and ex situ contact resistance (CR) determination [9] have been described elsewhere.

Single cell experiments at the cathode side were carried out with a commercial CCM based on Nafion 115. Platinum-coated Ti mesh-type PTLs were used on both sides and, additionally, carbon paper was sandwiched between the PTL and the CCM at the cathode side. Testing was carried out in ultra-pure water at $60^{\circ} \mathrm{C}$ and ambient pressure. A mixed bed (strong $\mathrm{acid} /$ strong base) ion-exchange resin was deployed in the cell setup for inline water purification. Contact resistance of $316 \mathrm{~L}$ and $\mathrm{C}-316 \mathrm{~L}$ was measured by sandwiching them between two carbon paper sheets between two identical gold-plated copper cylinders. The assembly was installed in a hydraulic press and pressure was applied in $16 \mathrm{~N} \mathrm{~cm}^{-2}$ steps from $16 \mathrm{~N} \mathrm{~cm}^{-2}$ to $160 \mathrm{~N} \mathrm{~cm}^{-2}$. The goldplated copper cylinders were connected to a current source and a constant current was applied. The resulting voltage drop was recorded for each pressure step to calculate the total resistance. The contact resistance can be calculated by comparison of the total resistance of the setup and a single carbon paper sheet.

\section{Results and Discussion}

Fig. 1 presents the results of PEM electrolysis single cell tests in which $316 \mathrm{~L}$ and $\mathrm{C}-316 \mathrm{~L}$ were used as end-flow plates. In addition, an in situ reference electrode [5] was placed at the surface of the respective plates and, as expected, the potential at the plate surface was far below the potential in the anode catalyst layer. An additional 30day $(720 \mathrm{~h})$ test with $\mathrm{C}-316 \mathrm{~L}$ was carried out (not shown).

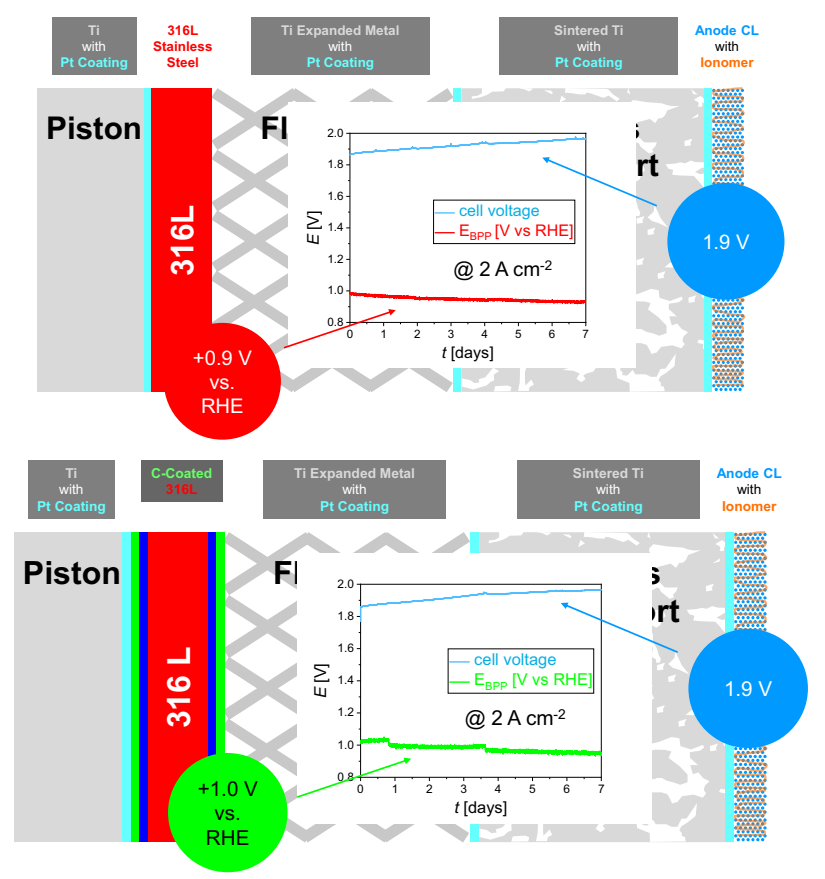

Fig. 1. Ionic decoupling in single cell PEMWE experiments with an in situ reference electrode at the anode side, with $316 \mathrm{~L}$ (top) and C-316L (bottom) flow plates. The potential at the endflow plates, red trace (top) and green trace (bottom) is much less oxidative than suggested by the cell voltage, blue trace (top and bottom). The results indicate relatively mild conditions under which both stainless steel and carbon are stable.

Post mortem analysis of the plates via AES sputter depth profiling indicated the absence of corrosion of the $316 \mathrm{~L}$ material and the absence of bulk carbon oxidation on $\mathrm{C}-316 \mathrm{~L}$ in all cases ( 7 and 30 days). Furthermore, digestion and ICP-SFMS analysis of the CCMs at the end of the tests showed no contamination with typical elements present in stainless steel, i.e., $\mathrm{Cr}, \mathrm{Mn}$, and $\mathrm{Fe}$. The clear advantage of the carbon-coated material over its uncoated counterpart is found in substantially reduced contact resistance, which was measured ex situ under conditions obtained from the in situ experiments in Fig. 1 (7 days, $60^{\circ} \mathrm{C}, 0.9 \mathrm{~V}$ vs RHE, sulfuric acid $\mathrm{pH} 4.5$ ). The ex situ measurements were necessary due to surface contamination of the in situ plates with Ru deposits likely originating from the CCM.

By definition, a bipolar plate is exposed to both anode and cathode conditions. Thus, the behaviour of $316 \mathrm{~L}$ and $\mathrm{C}-316 \mathrm{~L}$ was also investigated as end-flow plate at the cathode side of a PEMWE. Fig. 2 shows the temporal evolution of the cell voltage of two single cell PEM electrolysis experiments at a constant applied current density of $2 \mathrm{~A} \mathrm{~cm}^{-2}$ with $316 \mathrm{~L}$ and $\mathrm{C}-316 \mathrm{~L}$, respectively, as cathode flow plates. The cell voltage degradation is in both cases about $77 \mu \mathrm{V}$ per hour and both plates exhibit similar behaviour. The notion that cell degradation is independent of the choice of the cathode end-flow plate $(316 \mathrm{~L}$ vs. C-316L) is corroborated in polarization curves and electrochemical impedance spectroscopy (not shown). 


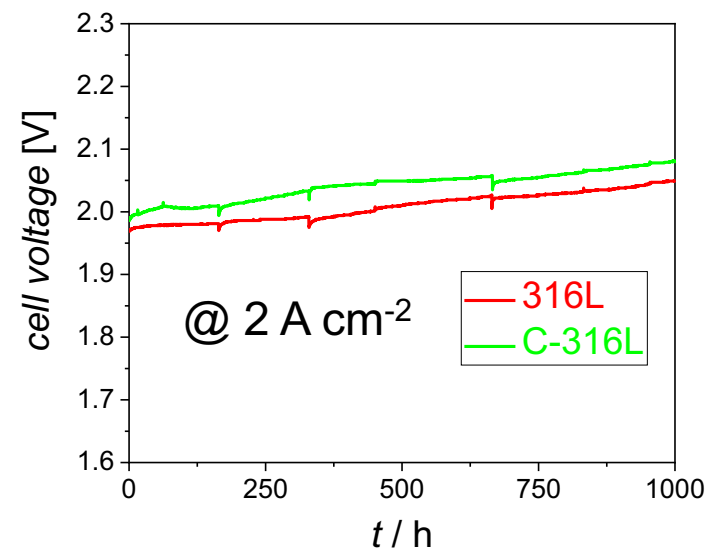

Fig. 2. PEMWE single cell experiments with $316 \mathrm{~L}$ (red trace) and $\mathrm{C}-316 \mathrm{~L}$ (green trace) as end-flow plates at the cathode side.

Contact resistance measurements for the cathode flow plates are presented in Fig. 3. The C-316L plate shows a significantly lower CR than $316 \mathrm{~L}$ while in both cases deterioration of the $\mathrm{CR}$ due to electrolyzer operation is absent. The difference in contact resistance is small in single cell tests but becomes more important in the construction of stacks from cells connected in series. The plates will be investigated by AES sputter depth profiling to investigate changes in the oxide (passive) layer of the stainless steel and the carbon-coating.

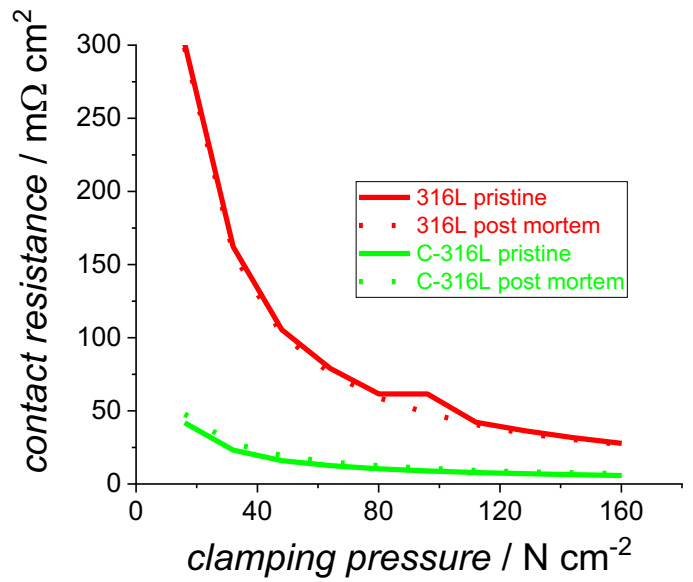

Fig. 3. Contact resistance measurements of $316 \mathrm{~L}$ and $\mathrm{C}-316 \mathrm{~L}$ flow plates before (pristine) and after (post mortem) $1000 \mathrm{~h}$ operation at the cathode of a PEMWE at $2 \mathrm{~A} \mathrm{~cm}^{-2}$.

In summary, the suitability of $\mathrm{C}-316 \mathrm{~L}$ as the end plate material at the anode and cathode side of a PEM water electrolyzer has been demonstrated. Hence, we suggest carbon-coated stainless steel as a cost-effective and scalable solution to replace Pt-coated titanium bipolar plates. The ionic decoupling effect which makes the substitution possible also holds great promise to reduce costs of the anode PTL.

\section{References}

1. K. Ayers, Curr. Opin. Electrochem., 18, 9 (2019)

2. M. Carmo, D.L. Fritz, J. Mergel, D. Stolten, Int. J. Hydrogen Energy, 38, 4901 (2013)

3. International Technology Roadmap for Photovoltaic (ITRPV) 2020 Results (2021)

4. J. Arbib, A. Dorr, T. Seba, Rethinking Climate Change, RethinkX, 26 (2021)

5. E. Brightman, J. Dodwell, N. van Dijk, G. Hinds, Electrochem. Commun. 52, 1 (2015)

6. Q. Feng, X.Z. Yuan, G. Liu, B. Wie, Z. Zhang, H. Li., J. Power Sources, 366, 33 (2017)

7. H. Becker, L. Castanheira, G. Hinds, J. Power Sources, 448, 227563 (2020)

8. T. Novalin, B. Eriksson, S. Proch, U. Bexell, C. Moffatt, J. Westlinder, C. Lagergren, G. Lindbergh, R. Wreland-Lindström, Int. J. Hydrogen Energy, 46, 13855 (2020)

9. S. Proch, M. Stenström, L. Eriksson, J. Andersson, G. Sjöblom, A. Jansson, J. Westlinder, Int. J. Hydrogen Energy, 45, 1313 (2020) 